\title{
Crown dynamics of Brazilian pine (Araucaria angustifolia) in Santa Catarina region of Brazil
}

\author{
André Felipe Hess ${ }^{1 *}$, Ana Claudia da Silveira ${ }^{1}$, Sandra Mara Krefta ${ }^{1}$, Diego Vinchiguerra dos Santos ${ }^{1}$, \\ Mushue Dayan Hampel Vieira Filho ${ }^{1}$, Kemely Alves Atanazio ${ }^{1}$, Luis Paulo Baldissera Schorr ${ }^{1}$, Isadora de \\ Arruda Souza ${ }^{1}$, Geedre Adriano Borsoi ${ }^{1}$, Thiago Floriani Stepka ${ }^{1}$, Emanuel Arnoni Costa ${ }^{2}$, Veraldo \\ Liesenberg ${ }^{1}$
}

\author{
${ }^{1}$ Department of Forest Engineering, Santa Catarina State University, 2090 Luiz de Camões Avenue, Lages, Santa \\ Catarina State, Brazil. Postal Code: 88520-000 \\ ${ }^{2}$ Department of Forest Engineering, Federal University of Santa Maria, 1000 Roraima Avenue, Santa Maria, Rio \\ Grande do Sul State, Brazil, Postal Code: 97105-900
}

*Corresponding author: hessandre@yahoo.com.br

Abstract

Generatation of models for the management of Araucaria forests in southern Brazil using morphometric relationships with density is still scarce. Changes in the dynamics of the shape and size of trees in the forest indicate the need to regulate the density of trees (silvicultural intervention) or self-adjustment of the species to shape structure, living space, competition, growth rate and resource use. Trees with larger crowns show higher growth rate and their size inform the vital space of growth and support management density of the forest. This information is important to support forest management and can be used to build individual tree growth models. Management models built based on the relationship between forest density and morphometric variables are powerful tools to achieve sustainable yield. Thus, the purpose of this study was to adjust equations to express the diameter, the shape of the crown in function of morphometric/dendrometric variables and to relate the dynamics of the changes in crown surface area and the number of trees per hectare with the diameter and crown surface area. Morphometric and dendrometric data were measured from individual trees in 25 permanent plots located in 84 hectares of a natural forest with predominance of Araucaria angustifolia (Bertol.) Kuntze species. The diameter at breast height, total height, crown insertion height and four crown radius were measured, including 330 trees. The data were subjected to Pearson correlation analysis and regression conditioners (normality and homogeneity of variance). All the equations proposed in the objectives were generated using generalized linear models (GLM) techniques, which showed accuracy and precision with low values of deviation and Akaike criterion. The results showed that there is interaction between crown shape, density and diameter, indicated by Pearson correlation higher than 0.9. The interactions of crown and density variables identified requirements of silvicultural interventions and the period to perform these activities according to the mean diameter of the forest or to a desired diameter. This is important information for the conservation of the Araucaria Forest structure.

Keywords: morphometry, forest inventory, forest management, forest measurement, dendrometry.

Abbreviations: csa_crown surface area, GLMs_Generalized Linear Models, dbh_diameter at breast hight, cl_crown length, MOF_ Mixed Ombrophylous Forest.

Introduction

The morphometry of the crown is the study of the mathematics of shapes in the same population of trees (Burkhart and Tomé, 2012). Currently, the shapes and dimensions of trees and their modifications over time have acquired importance, given the possibility of adjusting statistical models of volumetric estimation, competition and growth (Figueiredo et al., 2014). With measurement of crown length and width, the crown surface and crown volume can be determined by assuming that the crown is regular geometric solid. It is common to assume that tree crowns are cones or paraboloids (Burkhart and Tomé, 2012). As to the shape of the crown, there are studies that relate this variable to the tree size, since they relate stability, vitality and productivity, besides allowing adjustment of competition and tree growth models (Wink et al., 2012). This justifies the use of morphology to evaluate the vitality of the tree (Bayer et al., 2013).

The tree crown structure is crucial in linking feedback between tree functioning, structure and environment. It is even more important in native forests, where different species demonstrate their ability to acclimatize their structure and compete for the same resources and space (Pretzsch, 2009).

Attributes of crown are important in many physiological processes and influence in the growth rate, growth of trunk diameter, fruit and seed production among others 
(Kozlowski and Pallardy, 1996). The growth depends on the light quantity absorbed by leaves, also on the efficiency of the conversion of light absorbed in biomass and allocation of photoassimilates in tissues (Binkley et al., 2013). In general, competition among trees has a negative effect on resources availability for individual trees, which is reflected in a decline in growth with an increase in competition from neighbouring trees (Coates et al., 2009).

The crown is the component of the tree responsible for the absorption of light. According to Binkley et al. (2013), the absorption of light by leaves is the foundation for all production of trees and stands. The growth of both trees and stands in part depends on the amount of light absorbed by leaves, but also on the efficiency of converting absorbed light into biomass, and the allocation of photosynthate to various tissues. Studies comparing growth differences in species existence (within sites), site fertility (with constant species composition), and silvicultural treatments (within sites) show that typically higher growth rates are associated with $50-80 \%$ greater absorption of light.

Same authors reported that the development of individual tree crowns has been characterized by crown dimensions (such as the live crown ratio of the foliated length of the stem as a proportion of total stem height) and individual tree leaf area (often estimated from diameter, or from crosssectional sapwood area). Canopy development for stands has been indirectly indexed by measurement of stand basal area or stand density index. The stands with low basal area typically grow less than stands with moderate or high basal areas, largely owing to smaller canopies and lower absorption of light. This information is important as it demonstrates the need for interventions on forest density throughout its development. This allows maintaining the growth rate for individual trees, adequate canopy, dimension and projection of the crown, resources supply and forest structure.

The crown efficiency allows identification of the least efficient trees (Sterba et al., 1993; Reid et al., 2004; Gspaltl et al., 2012). It can be used to determine trees to be removed in thinnings (Sterba and Amateis, 1998). The knowledge of the efficiency of trees is essential for the establishment of structured stands that increase the efficiency of the use of tree resources and the production at the level of stands (Gspaltl et al., 2013). Additional information on the definition of silvicultural in mixed forests with uneven age such as Araucaria in southern Brazil is important to favor larger growth trees for a same crown projection area.

According to Padoin et al. (2010), several indices obtained between crown and trunk dimensions to describe the growth and production capacity of trees and forest. In particular, the relationships between crown diameter, tree height and diameter, and crown diameter and length are very important in competition studies of forest stands, supporting future thinning decisions. According to Leite et al. (2012), the dimensions of the crown interfere with the accomplishment of the physiological processes and these are often used as indicators for ability of trees to compete for resources.

Research in alternative management and silvicultural options requires years or decades of monitoring after harvesting. However, it is impracticable to apply this type of research in native Araucaria Forests in Brazil because current laws restrict forest management by prohibiting the harvest of the most important timber tree species found in this forest type, including Araucaria angustifolia (Brazilian pine) (Orellana et al., 2017).

However, the restriction by law does not ensure the future conservation of the species with less diametric structure, because what is perceived is the occurrence of extreme competition between trees, damaged crowns and reduced increment rates (Hess et al., 2016). Therefore, it is necessary to formulate management models that demonstrate the possibility of intervening the forest without harming the conservation of the species or causing its extinction.

The formulation of models using relationships between crown variables and density (number of trees per hectare) may show legal authorities that there is a need for silvicultural intervention to reduce competition to favor the growth, yield and production of the species. This proposition is related to modelling for individual trees. In this study, the individual relationship of each tree in the forest with change of crown shape and the number of trees per hectare over time were assessed.

Many authors have stated that individual-tree growth models have several advantages over size-class or wholestand growth models for supporting forest management in uneven-aged forests (Vanclay 1994; Zhao et al., 2004; Weiskittel et al. 2011; Orellana et al., 2017). The predictions based on individual trees can accommodate different species, densities, management regimes, and regeneration methods (Pretzsch, 2009). Individual-tree growth models attempt to simulate the competitive environment of each tree (Davis et al., 1987), providing maximum detail and flexibility for evaluating the alternative utilization options and stand treatments (Avery and Burkhart 2002; Orellana et al., 2017).

The main aim of this study is to show that silvicultural interventions are necessary for the conservation of the species, structure of the forest, increment rate and its diversity. This improves forest management, policies and promotes the development of old-growth characteristics in managed forest landscapes.

Montigny (2004) showed that employing of silvicultural systems and treatments is necessary to create diversity in forest structure that results in a variety of canopy layers (vertical structure) and spatial patchiness (horizontal structure) to enhance biodiversity and wildlife. A STEMS experiment examined seven different treatment regimes such as extended rotation along with commercial thinning (Montigny, 2004). These silvicultural regimes created a range of gap sizes and frequencies that emulate natural variation in the forest structure.

Therefore, the main problem is to aggregate information of the changing dynamics of the shape and surface area of the crown with the increase in diameter and density, mainly to accommodate the vital space conditions per individual tree, competition for resources and maintenance of the growth capacity of trees. This information is fundamental to propose silvicultural interventions and for the forest management in uneven-aged forests because sometimes it is not possible to know the age of trees.

The hypothesis of this study was to verify if the crown morphometry for different tree diameters and their density can be used as indicators of silvicultural interventions and to test if this information is useful to understand the dynamics 
of natural araucaria forest. The objective of this study was to adjust equations to explain the tree crown shape dynamics of Araucaria angustifolia (Brazilian pine) for different diameters classes and densities, as well as to propose silvicultural interventions with the information among crown variables, diameter and number of trees per hectare to contribute conservation of the species.

\section{Results and discussion}

\section{Analysis of the diametric structure for araucaria forest to adequacy of the density and shape of the crowns}

The sampling adequacy indicated the need for 25 sample plots, which were used to develop this work. With the inventory data, the diameter distribution of the forest was obtained and characterized by the J-inverted shape (Fig. 1), which represents the largest number of individuals in the smallest diameter classes and a total of 330 trees per hectare. The distribution presents the possibility of intervention based on the model for uneven-aged forests proposed by Liocourt. The coefficients of the equation (10) were $b_{0}: 5.04098$ and $b_{1}:-0.05678$.

The adjustment of equation 10 and the Fig. 1 showed that there is an excess of trees in the diametric classes of 35 to $50 \mathrm{~cm}$ and the need for an increase in the number of trees in the diametric classes of 10 to $30 \mathrm{~cm}$ and 55 to $70 \mathrm{~cm}$, by which the forest presents a balanced structure. This result demonstrates that the lack of intervention and management compromises the maintenance of the future diameter structure with larger diameter or old-grown trees (Sullivan and Sullivan, 2016), natural regeneration, ingress and stagnation of the diametric increment rate.

Unmanaged forests have lower increment rates in the smaller diameter classes. However, this is not the growth pattern indicated for the perpetuity of the individual tree structure in the forest. Thus, the opening of the canopy with silvicultural intervention may provides conditions for the maintenance of the dynamics of the growth and conservation of species, mainly due to the predominance of A. angustifolia in the Mixed Ombrophylous Forest, a species with higher commercial value and historical importance for the development of the Southern Brazil.

With this data set, it was possible to obtain the descriptive statistics of the dendrometric and morphometric variables for the studied species (Table 1), the Pearson correlation, (Table 2), the model adjustments and the graphical relationships between morphometric variables to model the crown shape (Fig. 2). Crown rays equal to zero mean that in some direction the crown was broken because of the competition or physical damages.

\section{Correlation among inter-dimensional variables for model fit and silvicultural intervention}

Pearson's correlation showed values higher than 0.4 for predictor variables and positive correlations. The diameter at breast height (dbh) was the predictor variable with the highest correlation between dendrometric and morphometric variables, being able to generate its estimate as a function of the explicative independent variables, height (h), crown length (cl), outer crown radio (ocr) and inner crown radio (icr). The predictive variable, shape of crown, was evaluated by (cl) as a function of (ocr) and (icr) which presented lower values of correlation. The fitted models can be generated (Fig. 2B), in which the values explain the ontogenetic variation of the tree crown shape according to the density, competition, age and site, not presenting high values of correlation due to its great variability.

The positive Pearson correlation of the variables (morphometric and dendrometric) with the crown surface area indicated the need for lateral space to expand the crown, its vitality and the photosynthetic production for growth. High correlation with diameter (dbh) indicates dominant trees and past capacity to win the competition by occupy the upper canopy. Thus, the variables were defined to adjust the models of crown shape, crown surface area (csa), number of trees per hectare ( $N / h a)$ as a function of ddh and csa (Table 3 ) to identify periods for silvicultural interventions (Fig. 4A and B). The fitted by the GLMs technique showed better results in the field of random distribution gamma and identity function.

Fig. 2 ( $A$ and $B$ ) shows that the larger the crown radius, larger the crown length, indicating the need for lateral space for expansion, avoiding self-thinning of the lower branches, competition and light insufficiency at the crown base, maintaining the photosynthetic capacity and growth of individual trees in the forest.

It can be inferred that the variable crown length and crown surface area are parameters to estimate the required living space when forest management is desired for a given diameter, and they can be used to infer the silvicultural intervention planning (Nutto et al., 2001). Thus, considering that the crown is the organ responsible for the photosynthetic process, the analyzed variables are directly related to the growth, production, and consequently density of trees.

The estimates for the ( $\mathrm{dbh}$ ) as a function of dendrometric and morphometric variables presented adequate fit. The precision (Fig. 3A) and homogeneous residuals (Fig. 3B), without discrepant points, generated a few outliers for the largest diameters. The outliers might be be due to the smallest number of trees in this class and crown defects due to the competition or environmental damage (wind, broken crown, absence or lesser crown radius). However, the use of the equation (eq. 8) is appropriate to generate estimates for this variable.

The interactions between diameter classes, crown surface area (csa) and density ( $\mathrm{N} / \mathrm{ha}$ ) were represented in Fig. 4 (A and $B)$. This indicats the point where intervention is required for a given diameter, crown surface area and number of trees per hectare. The maximum degree of the ground coverage by crowns $\left(100 \mathrm{~m}^{2}\right)$ was occured with a dbh of 45 $\mathrm{cm}$. The ideal density would be 19 trees per hectare for this $\mathrm{dbh}$ class, when the management goal is this average diameter. Fig. $4 \mathrm{~A}$ shows that the measures that increase the crown surface area and the diameter makes it necessary to reduce the number of trees per hectare to allow the increase in crown surface area for trees of the smaller classes due to the growth dynamics. 
Table 1. Dendrometric and morphometric parameters of individual trees in native forest from Araucaria angustifolia in Santa Catarina, $n=330$ trees/ha.

\begin{tabular}{llllllllll}
\hline Statistics & $\mathrm{dbh}(\mathrm{cm})$ & $\mathrm{h}(\mathrm{m})$ & $\mathrm{cih}(\mathrm{m})$ & $\mathrm{cd}(\mathrm{m})$ & $\mathrm{ocr}(\mathrm{m})$ & $\mathrm{cl}(\mathrm{m})$ & $\mathrm{icd}(\mathrm{m})$ & $\mathrm{icr}(\mathrm{m})$ & $\mathrm{csa}\left(\mathrm{m}^{2}\right)$ \\
\hline Mean & 29.0 & 16.2 & 11.0 & 5.5 & 2.8 & 5.2 & 1.9 & 0.9 & 60.5 \\
Maximum & 70.0 & 26.5 & 19.3 & 14.4 & 7.2 & 14.9 & 6.9 & 3.4 & 287.5 \\
Minimum & 10.2 & 6.4 & 3.1 & 0.5 & 0.2 & 0.5 & 0 & 0 & 1.1 \\
$\sigma$ & 11.5 & 3.7 & 6.0 & 0.9 & 0.5 & 2.3 & 0.8 & 0.4 & 40.1 \\
\hline
\end{tabular}

Where: dbh: diameter at breast height in $\mathrm{cm}$; h: total height in $\mathrm{m}$; cih: crown insertion height in $\mathrm{m}$; cdo: crown diameter in $\mathrm{m}$; ocr: outer crown radius in $\mathrm{m}$ : cl: crown length in $\mathrm{m}$; icd: inner crown diameter in $\mathrm{m}$; icr: inner crown radius in $\mathrm{m}$; csa: crown surface area in $\mathrm{m}^{2}$; $\sigma$ : standard deviation.

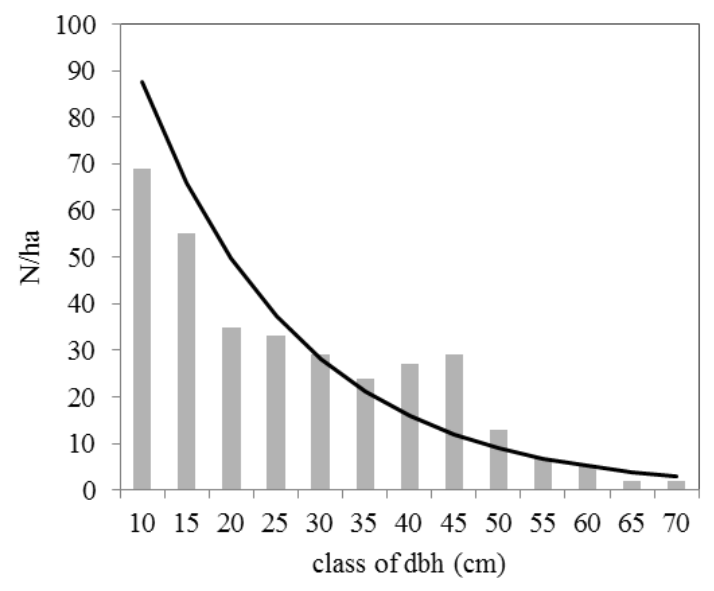

Fig 1. Diametric distribution (dbh) and number of trees per hectare (N/ha) by diameter class in natural forest within 84 ha of Araucaria angustifolia in Lages, Santa Catarina State, Brazil. Full line represents the estimated frequency of the N/ha, fit by Meyer equation, $R^{2}$ aj. 0.87 and standard error of estimate: 0.42 .

Table 2. Pearson analysis correlation between dendrometric and morphometric variables to fit models of their relationships for Araucaria angustifolia in Santa Catarina.

\begin{tabular}{lllllll}
\hline$*$ & $\mathrm{dbh}$ & $\mathrm{h}$ & $\mathrm{cl}$ & $\mathrm{ocr}$ & $\mathrm{icr}$ \\
\hline $\mathrm{dbh}$ & 1 & 0.74 & 0.52 & 0.80 & 0.72 & 0.80 \\
$\mathrm{~h}$ & - & 1 & 0.50 & 0.55 & 0.44 & 0.60 \\
$\mathrm{cl}$ & - & - & 1 & 0.44 & 0.40 & 0.70 \\
$\mathrm{ocr}$ & - & - & - & 1 & 0.73 & 0.92 \\
$\mathrm{icr}$ & - & - & - & - & 0.68 \\
$\mathrm{Csa}$ & - & - & - & - & 1 \\
Where: dbh: diameter at breast height in $\mathrm{cm}$; $\mathrm{h}$ : total height in $\mathrm{m}$; ocr: outer crown radius in $\mathrm{m}$ : cl: crown length in $\mathrm{m}$; icr: inner crown radius in $\mathrm{m}$; csa: crown surface area in $\mathrm{m}^{2}$. (*): all variables with prob. P $<0.0001$.
\end{tabular}

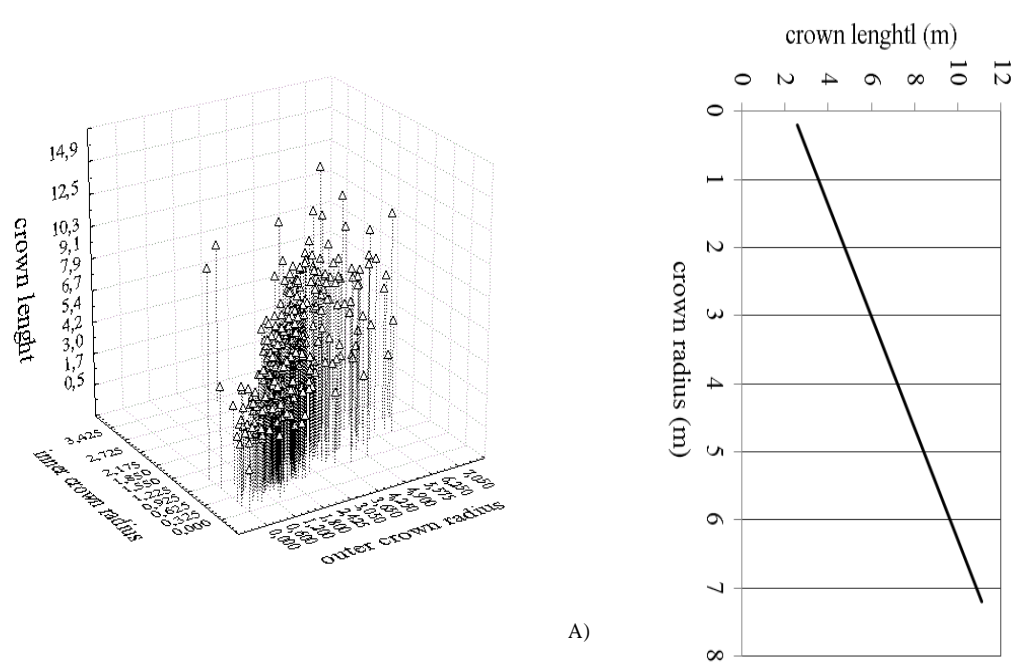

B)

Fig. 2. Crown shape of the araucaria trees, showing need for lateral space to expand the crown and adequacy of density to support its growth. (A) Three-dimensional interpretation of the relation between (cl) crown length, (ocr) outer crown radius and (icr) inner crown radius. B) Shape of crown represented by the ratio of crown length as a function of the outer and inner crown radius fitted by mathematical equation. 
Table 3. Mathematical equations and adjustment accuracy statistics for interactions between shape, density and size of Araucaria angustifolia in Santa Catarina.

\begin{tabular}{|c|c|c|c|c|}
\hline Equation & $D$ & AIC & $\mathrm{BIC}$ & LF \\
\hline $\mathrm{csa}=-14.5685+2.6524 * \mathrm{dbh}$ & 0.2 & 105.1 & 106.8 & $G-\mu$ \\
\hline $\mathrm{N} / \mathrm{ha}=51.3862-0.7115 * \mathrm{dbh}$ & 1.8 & 89.7 & 91.4 & $G-\mu$ \\
\hline $\mathrm{N} / \mathrm{ha} 15 \%=43.6055-0.611 * \mathrm{dbh}$ & 2.4 & 86.8 & 88.5 & $G-\mu$ \\
\hline $\mathrm{N} / \mathrm{ha}=4.4655-0.0171 * \mathrm{csa}$ & 1.1 & 83.5 & 85.2 & $G-\ln (\mu)$ \\
\hline $\mathrm{dbh}=-10.3914+1.3964 * \mathrm{~h}+3.8208 *$ ocr $+6.0836 * \mathrm{icr}$ & 17.9 & 2133 & 2152 & $G-\mu$ \\
\hline $\mathrm{cl}=2.3438+0.6507 * \mathrm{ocr}+1.1351 * \mathrm{icr}$ & 77.7 & 1481 & 1496 & $G-\mu$ \\
\hline
\end{tabular}

Where: csa: crown surface area in $\mathrm{m}^{2} ; \mathrm{N} /$ ha: number of tree per hectare; dbh: diameter at breast height in $\mathrm{cm}$; cl: crown length in $\mathrm{m}$; $\mathrm{h}$ : total height in $\mathrm{m}$; ocr and icr: outer and inner crown radius in $\mathrm{m}$; $D$ : deviance; AIC: information criterion of Akaike; BIC: information criterion of Baynesian; LF ( $G-\mu$ ): identity link function, gamma distribution; $G-\ln (\mu)$ : logarithmic link function, gamma distribution.
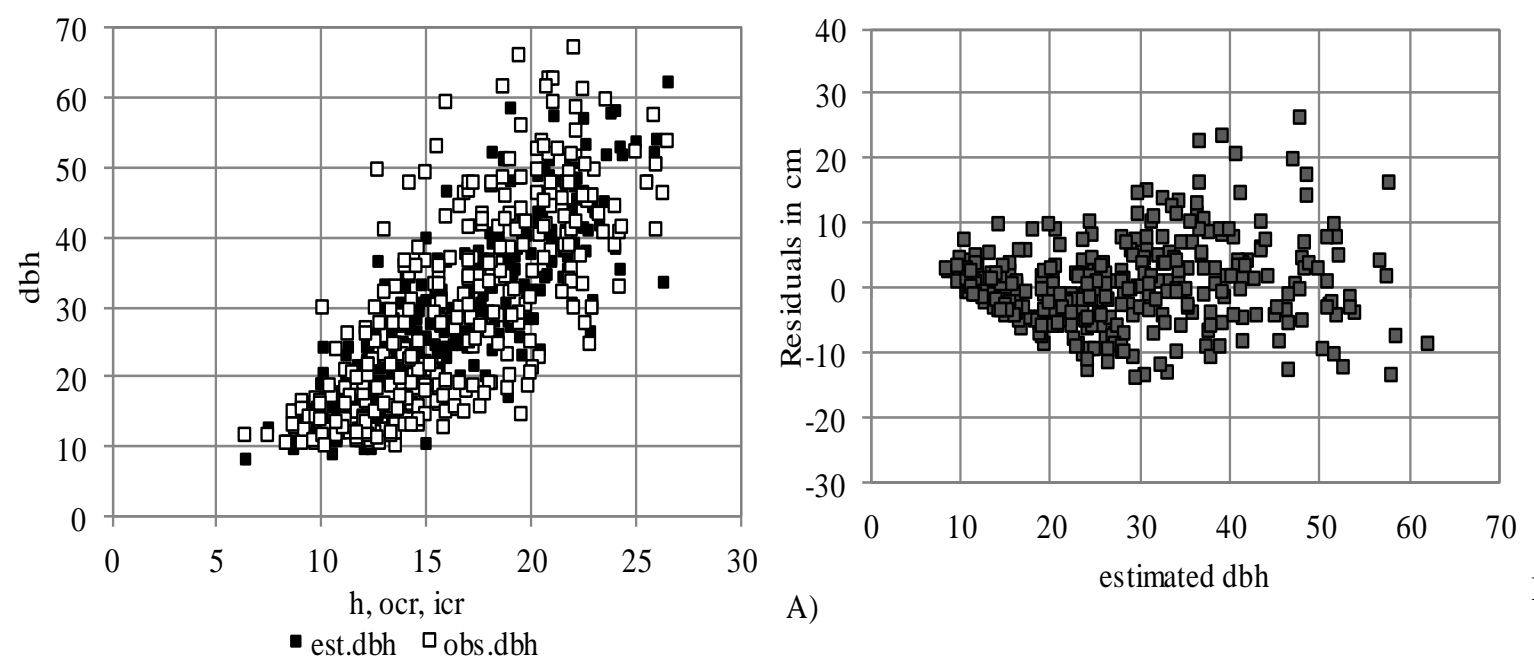

B)

Fig 3. Estimation of diameter at breast height (dbh) with dendrometric and morphometric variables. A) Accuracy of the estimated diameter as a function of dendrometric and morphometric variables, based on the estimated and observed value. B) Distribution of the residuals of the equation to adjust the diameter at breast height. est. dbh: estimated dbh by equation; obs. dbh: observed values (measured in inventory).
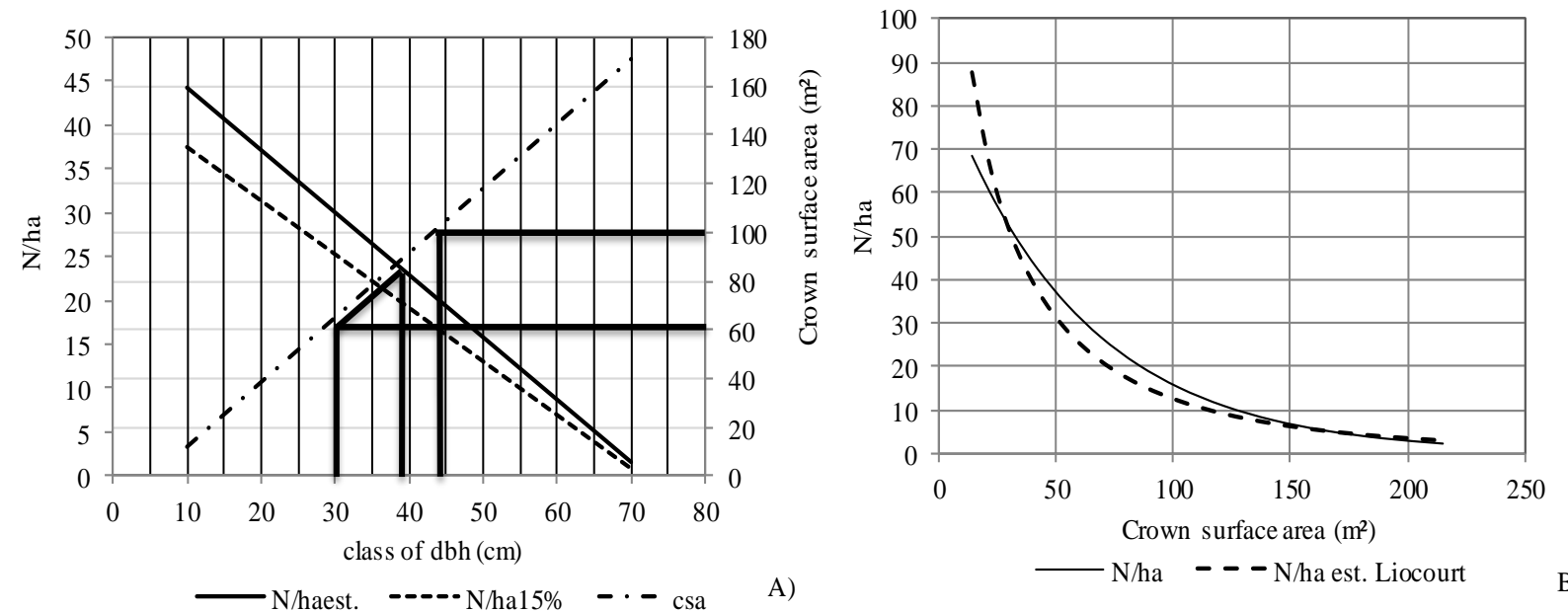

Fig 4. Proposal of silvicultural intervention based on the relationship between dendrometric and morphometric variables. (A) Interdimensional relationships of crown surface area (csa), number of trees per hectare estimated (N/ha est.) and dynamics of growth in diameter identifying the silvicultural intervention with a $15 \%$ (dotted line) reduction in the number of trees per hectare and per diameter class for Araucaria angustifolia in Santa Catarina. B) Indicative of the excess of the number of trees per hectare as a function of the crown surface area corresponding to the major diameter trees, corroborating with the Liocourt method of reducing density. Lines ( - ) in the figure (A) represent the current mean in diameter $(30 \mathrm{~cm})$, mean in crown surface area $\left(60 \mathrm{~m}^{2}\right)$ and, the possibility to silcicultural intervention when when the $\mathrm{dbh}$ reaches $40 \mathrm{~cm}$, before the crown surface area reach occupancy of the $100 \mathrm{~m}^{2}$ for individual trees in the forest ( $\mathrm{dbh}$ of $45 \mathrm{~cm}$ ). 
The intervention point should occur before the crown surface area reaches $100 \%$ of occupancy, which must occur before the average diameter reaches $40 \mathrm{~cm}$ dbh (crossing point of the curves between density and crown surface area).

Currently, the average forest $\mathrm{dbh}$ is $30 \mathrm{~cm}$ and the (csa) is $60 \mathrm{~m}^{2}$. However, Fig. 1 and Fig. $4 \mathrm{~B}$ show that to maintain growth dynamics in crown surface area and diameter, there is a need to remove trees in the diametric classes from 35 to $50 \mathrm{~cm}$, which have excess of trees, corresponding to the greater crown surface area. This intervention allows the opening of canopy to promote the growth of trees in smaller classes, natural regeneration and increment in diameter. Thus, aiming a forest management for an average diameter of $40 \mathrm{~cm}$ (crossing point of the curves) may require an intervention with a reduction of $15 \%$ in the number of trees per hectare per dbh class (range of management). That is indicated by the first line fitted of the number of trees per hectare and percentage of excess trees in the surplus classes.

According to Pretzsch (2014), canopy structure and tree crown morphology affect the conditions of forests, tree growth and many other forest functions. For this, obtaining crown surface area estimates and their changes with the increase in diameter as well as the regulation of forest density are efficient tools for the forest management.

The results demonstrate the effect of the change of these variables on the structure and dynamics of the forest. Because the large crown size accompanies with the diameter of the tree. The greater exploitation of resources and repression effects of competitors (Pretzsch et al., 2012), indicates that identification of intervention in density is more required to maintain the continuity of individual tree growth and to accommodate the larger size and crown area. This was demonstrated by the $\mathrm{N} / \mathrm{ha}$ as a function of the (dbh) and (csa) (Fig. 4A and 4B), with the crown expansion variation causing changes in spatial occupation. It results in a gradual decrease in the number of trees per hectare. The relation between (csa) and (N/ha) is an antagonistic or inversely proportional forces, because the increase in $\mathrm{dbh}$ enhances csa occupied by the individual tree, requiring a larger occupation space for each tree, imposing the forest and the manager to decrease the density.

The vertical and lateral expansion of the crown indicates the tree's space occupation and competitive status. The competition can squeeze or stretch the crown causing variation in forest structure and different conditions for growth. By forming environmental conditions within the forest (interception of light and precipitation), the canopy and crown structure is crucial for the feedback between structure-environment-growth, which drives population dynamics (Pretzsch, 2014).

In addition, the results show that the tree surplus (Liocourt method) coincides with the larger crown surface areas, indicating the need to remove trees in these diameter classes. This represents that trees have obtained the best growth conditions in the past (access to light, resources of soil and space), implying a relative advantage over competing trees.

This study reflects the forest dynamics, when with the passage of time it is necessary to interfere with density of the forest to follow the development structure of crown morphology and diameters. The programmed interventions will allow trees with smaller diameter to have similar growth conditions than those of larger diameter, freeing them from competition, increasing their crown surface areas, increment rate and number of trees, since their density is lower than necessary by the Meyer frequency distribution (Fig. 1). This knowledge shows the interrelations between structure and process in the dynamics of the forest.

It is important to emphasize that the remnants of the Mixed Ombrophilous Forest have been conducted without forest management for more than four decades, which makes difficult to know a pattern for the morphometric variables. They present variations for the same diameter class requiring greater caution to indicate a management plan. However, the lack of management leads to the development of a future diametric structure for this forest, because for a balanced structure there would be a need for a larger number of trees in the smaller diameter classes than the currently found.

Furthermore, the results show that there was an implication in the development of form and function for some individual trees in the forest. This may have been generated by past competition. It is not occurring in change between the size of tree's first component (crown) and second component (diameter), by which the distribution coefficient for the resource to the growth disproportionate among the individual trees. These relationships have been proved by the value of the coefficients of the regression equations, since the higher values will induce higher crown occupancy degree, competitiveness and lower number of trees.

The results of the correlation analysis between morphometric and dendrometric variables reflect the plasticity, by which the tree crowns can occupy the space (Pretzsch et al., 2012), by which the highest values in diameter and smaller with height. The higher correlations of the crown surface area with diameter and crown radius explain the relationship with the lateral expansion of the crown, while with height it refers to the vertical expansion of the crown. Thus, it can be inferred that the lateral space is vital for the formation of the crown, and vitality diameter growth. In view of this new evidence, silvicultural interventions are necessary to eliminate competition and to promote the development of the future forest structure.

Analysis of individual trees show how demand for resource and growth space increase as plants growth in size. In addition, if resources are no longer enough for all individuals in unmanaged forests, the self-thinning begins and the number of trees per hectare decreases. It can be assumed that the crown surface area is proportional to the growth space and quantity of resources (Pretzsch et al., 2012). According to the same authors, the average area of growth (unit area $=$ hectare) in relation to the number of trees is used as a substitutive variable for the average lateral expansion of the crown and individual tree resource demand. These relationships represent a link between the production of the average tree and the area or growth resources needed, and it is the union of production ecology and population ecology (Zeide, 1987).

The interactions between the morphometric and dendrometric variables mark the maximum possible density for a mean diameter of the trees and for the conditions of the study site. No-management strategy in the remnants of araucaria forest results the need for elaboration of specific 
studies in site if the management plans for the species are initiated, until the silvicultural interventions allow the development of a reference pattern for crown development and tree per unit area.

Density influences development of crown and diameter growth. In forests, adjustment of the equations describes how much resource or area of growth space is required to survive and grow in diameter. In addition, the distribution of trees in diameter class can be interpreted as an indication of future population growth (Easdale et al., 2007). Thus, we used these variables to demonstrate that the nomanagement policy is harmful for future development and structure of Araucaria Forest. There is a need for silvicultural intervention because only the conservation cannot guarantee the maintenance of the forest structure.

This implication was observed in the remeasurement of the diametric distribution of permanent plots in our studied area. The results showed that the number of trees in $10 \mathrm{~cm}$ class was decreased from 85 to 69 trees in a period of four years, with only three ingrowth and one mortality, while the other classes stagnated or inexpressively increased the number of trees with the current rate of increment.

Studies by Hess et al. (2016) demonstrated that implications of future diameter structure based on the analysis of increment rings for different diametric classes in four study regions in southern Brazil. The study showed that the smaller diameter classes grew less (in diamtere) than the larger trees in the past. The mean annual diametric increment of the lowest classes was $0.31 \mathrm{~cm} /$ year, while the other classes obtained increment from 0.6 to $0.9 \mathrm{~cm} /$ year.

In total, the morphometric and increment analyzes of this research corroborate with the need of silvicultural intervention in the Araucaria Forest, since there is a clear risk of implications on the structure, increment rate, species regeneration, genetic variability, production and the socioeconomic development in this important forest resource. Based on the average increment, this study indicates that the smaller trees will take 91 years to reach a diameter of $40 \mathrm{~cm}$.

\section{Materials and methods}

\section{Study area}

The study area is a natural forest of $A$. angustifolia (Brazilian pine), including trees with 13 and more then 70 years old (Ricken, 2014), located in the municipality of Lages, Santa Catarina State, at an altitude of $1,200 \mathrm{~m}$ with a total area of 84 ha and geographical coordinates of $27^{\circ} 49$ 'S and $50^{\circ} 06^{\prime}$ $W$. According to the Köppen classification, the municipality of Lages presents temperate $\mathrm{Cfb}$ climate that is constantly humid without dry season. The mean annual temperature is $15.2^{\circ} \mathrm{C}$ and the mean annual precipitation is $1,684.7 \mathrm{~mm}$ (Àlvares et al., 2013). The predominant vegetation is the Mixed Ombrophilous Forest typology, with predominance of A. angustifolia (Brazilian pine) species.

\section{Data collection}

The data were obtained from the measurement of individual trees in 34 permanent plots of $400 \mathrm{~m}^{2}(20 \times 20 \mathrm{~m})$, that were installed with a systematic sampling process, with between plots distance of $50 \mathrm{~m}$ and between lines of $100 \mathrm{~m}$ considered for the calculation of the sample adequacy an limit error of $10 \%$. In each plot, all trees with breast height (dbh) diameter from at least $10 \mathrm{~cm}$ were measured. The variables mensured were: dbh, total height (h), crown insertion height (cih), four outer crown rays (ocr) and four inner crown rays (icr) in the north, south, east, and west directions with the aid of compass and hypsometer Trupulse 200.

The following data were calculated for the crown length (cl) (eq. 1), crown surface area (csa) (eq. 2), the crown diameter (cd) (eq. 3) and the mean outer and inner crown radius $(\overline{o c r}, \overline{l c r})$ (eq. 4).

$\mathrm{cl}(\mathrm{m})=\mathrm{h}-\mathrm{cih}$

$\operatorname{csa}\left(\mathrm{m}^{2}\right)=\frac{\pi * \mathrm{~cd}}{2} \sqrt{\mathrm{cl}^{2}+{\frac{(\mathrm{cd})^{2}}{2}}^{2}}$

$\operatorname{cd}(\mathrm{m})=2 \cdot \overline{\mathrm{cr}}$

$\overline{\mathrm{ocr}}$ or $\overline{l c r}(\mathrm{~m})=\sum_{\mathrm{i}=1}^{\mathrm{n}=4} \mathrm{cr} / 4$

In addittion, we generated equations for (csa) in function for (dbh) (eq. 5), number of trees per hectare (N/ha) as a function of dbh (eq. 6) and (csa) (eq. 7). Tree diameter as a function of morphometric variables (h, ocr,icr) (eq. 8), shape of crown (cl) as a function of morphometric variables (eq. 9) and the adjustment of the Meyer frequency distribution (eq. 10).

csa $=b_{0}+b_{1} * d b h$

$\mathrm{N} / \mathrm{ha}=\mathrm{b}_{0}+\mathrm{b}_{1} * \mathrm{dbh}$

$\mathrm{N} / \mathrm{ha}=\mathrm{b}_{0}+\mathrm{b}_{1} * \mathrm{csa}$

$\mathrm{dbh}=\mathrm{b}_{0}+\mathrm{b}_{1} * \mathrm{~h}+\mathrm{b}_{2} *$ ocr $+\mathrm{b}_{3} * \mathrm{icr}$

$\mathrm{cl}=\mathrm{b}_{0}+\mathrm{b}_{1} *$ ocr $+\mathrm{b}_{2} * \mathrm{icr}$

$\ln \mathrm{N} / \mathrm{ha}=\mathrm{b}_{0}+\mathrm{b}_{1} * \mathrm{dbh}$

With the adjustment of equations 5, 6, 7 and 10 it was possible to analyze the interactions between size, crown surface area and density to propose silvicultural interventions for tree development and growth. With the readjustment of equation 6 and the difference between the current number and the adjusted for trees in each diameter class, it was possible to propose a reduction of $15 \%$ in the number of trees per hectare per diameter class.

\section{Data analysis}

The data of the dendrometric and morphometric variables were submitted to the Pearson correlation matrix $(r)$ of the predictor variables, since they are variables that present a linear correlation among one another Costa et al., (2016); Hess et al., (2016); Minatti et al., (2016); Roman et al. (2009). The variables with a correlation $(r)$ value higher than 0.4 and probability $(p<0.0001)$ were used to fit the models to explain the shape and dynamics of crowns and tree density in relation to the different diameters. 
In order to fit the models, the Generalized Linear Models (GLMs) technique was used, since the residues did not meet the normality conditions by the Shapiro-Wilk $W$ test ( $p$ $<0.0001$ ), and homogeneity of the variance, White's test ( $p$ $<0.0022$ ). The precision of the adjustment was evaluated by Deviance (D), Akaike (AIC), Baynesian (BIC) criteria, being lower values better the adjustment, residual distribution graph and graphical analysis of the relationships between variables. All adjustments were processed in the Statistic Analyses System program (SAS, 2004).

\section{Conclusion}

The study demonstrated the correlation between dendrometric and morphometric variables. With the linear regression adjustment it is possible to describe the dynamics of the crown changes with the increase in diameter and density adequate to the crown size, as well as to describe the crown shape for the several diameter classes. The interactions of crown and density variables allowed identification of silvicultural intervention requirements and the period to perform activities according to the mean diameter of the forest for a desired diameter, which is an important information for the conservation of the Araucaria Forest structure.

\section{Acknowledgements}

The authors are grateful for the support of the Santa Catarina State University, Department of Forest Engineering and its Graduate Program. The FAPESC - Foundation for Research Support of the Santa Catarina State - case number 2017TR639 - financial assistance for research groups and the owners of the Araucaria Forest for the availability of this study.

\section{References}

Àlvares CA, Stape JL, Sentelhas PC, Gonçalves JLM, Parovek G (2013) Köppen's climate classification map for Brazil. Meteorol Z. (22)6:711-728.

Avery TE, Burkhart HE (2002) Forest measurements. 5th ed. Long Grove (IL): Waveland Press, Inc.

Bayer D, Seifert S, Pretzsch H (2013) Structural crown properties of Norway spruce (Picea abies [L.] Karst.) and European beech (Fagus sylvatica [L.]) in mixed versus pure stands revealed by terrestrial laser scanning. Trees. 27:1035-1047.

Binkley D, Campoe OC, Gspaltl M, Forrester DI (2013) Light absorption and use efficiency in forests: why patterns differ for trees and stands. For Ecol Manag. 288: 5-13.

Burkhart HE, Tomé M (2012) Modeling forest trees and stands. New York: Springer.

Coates KD, Canham CD, LePage PT (2009) Above versus below ground competitive effects and responses of a guild of temperate tree species. J Ecol. 97(1):118-30.

Costa EA, Finger CAG, Fleig FD (2016) Influence of social position on the morphometrics relations in Araucaria angustifolia. Cienc Florest. (26)1:225-234.

Davis LS, Davis KP, Johnson KN (1987) Forest management. 3rd ed. New York (NY): McGraw-Hill.

Easdale TA, Allen RB, Peltzer, DA, Hurst JM (2012) Sizedependent growth responses to competition and environment in Nothofagus menziesii. For Ecol Manag. 270:223-231.

Figueiredo EO, Oliveira MVN, Fearnside PM, Papa DA (2014) Models to estimate volume of individual trees by morphometry of crowns obtained with lidar. Cerne. (20)4:621-628.

Gspaltl M, Sterba H, O'Hara KL (2012) The relationship between available area efficiency and area exploitation index in an even-aged coast redwwod (Sequoia sempervirens) stand. Forestry. 85:567-577.

Kozlowski TT, Pallardy SG (1996) Phisiology of woody plants. $2^{\text {nd }}$ ed. San Diego, Academis Press. 411p.

Hess AF, Loiola T, Souza IA, Nascimento B (2016) Morphometry of the crown of Araucaria angustifolia in natural sites in southern Brazil. Bosque. (37)3:603-611.

Leite LP, Zubizarreta-Gerendiain A, Robinson A (2012) Modeling mensurational relationships of plantationgrowth loblolly pine (Pinus taeda L.) in Urugay. For Ecol Manag. 289:455-462.

Minatti M, Hess AF, Ricken P, Loiola TM, Souza IA (2016) Shape and size relationships of Araucaria angustifolia in South Brazil. Afr J Agric Res. (11)41:4121-4127.

Montigny L (2004) Silviculture treatments for ecosystem management in the Sayward (STEMS): establishment report for STEMS 1, Snowden demonstration forest Res Br, B C Min For, Victoria, B C Tech Rep 17.

Nutto L, Tonini $H$, Borsoi GA, Moscovich FA, Spathelf $P$ (2001) Use crown parameters to evaluate the vital space in stands of Pinus elliottii Engelm. B Pesq Florest. 42:123-128.

Orellana E, Filho AF, Neto SP, Vanclay JK (2017) A distanceindependent individual-tree growth model to simulate management regimes in native Araucaria forests. J For Res-JPN. 22(1):30-35.

Padoin V, Finger CAG (2010) Relationships among the crown dimensions and the height of dominant trees in stands of Pinus taeda L. Cienc Florest. 20(1):95-105.

Pretzsch H (2014) Canopy space filling and tree crown morphology in mixed-species stands compared with monocultures. For Ecol Manag 327:251-264.

Pretzsch H, Matthew C, Dieler J (2012) Allometry of tree crown structure. Relevance for space occupation at the individual plant level and for self-thinning at the stand level. In: Matyssek R et al.(eds.), Growth and defence in plants, Ecological Studies 220, Springer-Verlag Berlin Heidelberg. Chapter 13.

Pretzsch H (2009) Forest Dynamics, growth and yield, from measurement to model. Springer, Berlin, Heidelberg.

Reid DEB, Lieffers VJ, Silins U (2004) Growth and crown efficiency of height repressed Lodgepole pine; are suppressed trees more efficient? Trees. 18:390-398.

Ricken P (2014) Increment, horizontal space and competition in natural population of Araucaria angustifolia in Santa Catarina plateau. Dissertation (Master in Forest Engineering - Area: Forest Engineering) - Santa Catarina State University. $105 \mathrm{f}$.

Roman M, Bressan DA, Durlo MA (2009) Morphometric variables and interdimensional relations for Cordia trichotoma (Vell.) Arráb. Ex.Steud. Cienc Florest (19)4:473480.

SAS Institute (2004) The SAS system for windows. Cary. Sterba H, Amateis RL (1998) Crown efficiency in a loblolly pine (Pinus taeda) spacing experiment. Can J Forest Res. 28:1344-1351. 
Sterba H, Andrae F, Pambudhi F (1993) Crown efficiency of oak standards as affected by mistletoe and coppice removal. For Ecol Manag. 62:39-49.

Sullivan TP, Sullivan DS (2016) Acceleration of old-growth structural attributes in lodgepole pine forest: Tree growth and stand structure 25 years after thinning. For Ecol Manag. 255:2718-2725.

Vanclay JK (1994) Modelling forest growth and yield: applications to mixed tropical forests. Wallingford: $C A B$ International.

Weiskittel AR, Hann DW, Kershaw Jr JA, Vanclay JK (2011) Forest growth and yield modeling. Chichester: WileyBlackwell.
Wink C, Monteiro JS, Reinert DJ, Liberalesso E (2012) Crown parameters and their relationship with diameter and height of Eucalyptus trees at different ages. Sci For. (40)93:057-067

Zhao D, Borders B, Wilson M (2004) Individual-tree diameter growth and mortality models for bottomland mixedspecies hardwood stands in the lower Mississippi alluvial valley. For Ecol Manag. 199:307-322.

Zeide B (1987) Analysis of the $3 / 2$ power law of self-thinning. Forest Sci. 33:517-537. 